\section{Genital warts: just a nuisance?}

There is unfortunately still a stigma attached to sexually transmitted diseases (STDs) which often results in a range of negative feelings experienced by patients. Genitourinary medicine clinics (GUMs) are well used to the shock expressed by many patients on being informed that they have contracted an STD. With many infections patients can be reassured that following a course of treatment they will be cured; this is not the case with viral infections. For these there is no cure and in the case of genital warts for which treatment can take several weeks, there may be recurrences. For women there is the fear of the link between genital warts and cervical cancer.

There is a paucity of research into the psycho-social and psycho-sexual problems associated with genital warts. However, what little there has been suggests that there is risk of adverse psychological effects. ${ }^{1-3}$

We tried to identify the nature of patients' feelings around the issues of having genital warts. One hundred and ten self completion questionnaires were filled in by patients with a new diagnosis of genital warts. Forty three patients still attending four weeks later completed a second questionnaire and comparisons between the two were made. A pilot study helped to identify answer categories, and questions allowed for multiple choice responses.

The newly diagnosed patients were asked "What were your feelings when you first knew you had warts?" and patients attending four weeks later were asked "What are your feelings now about having warts?" (table 1).

When asked "What are your feelings about the treatment?", less than half $(47 \%)$ of the newly diagnosed patients felt "Okay". (All results are rounded to the nearest whole figure.) Twenty six per cent felt embarrassed, $22 \%$ were worried about discomfort, $15 \%$ felt afraid or scared, $27 \%$ were concerned about

Table 1 Patients' feelings about having genital warts

\begin{tabular}{llc}
\hline & $\begin{array}{c}1 s t \text { Questionnaire } \\
(n=110)\end{array}$ & $\begin{array}{c}2 n d \text { Questionnaire } \\
(n=43)\end{array}$ \\
\hline Frightened/scared & $38(34 \cdot 5 \%)$ & $7(16 \cdot 3 \%)$ \\
Embarrassed & $61(55 \cdot 4 \%)$ & $16(37 \cdot 2 \%)$ \\
Dirty & $40(36 \cdot 4 \%)$ & $9(20 \cdot 9 \%)$ \\
Okay & $7(6 \cdot 4 \%)$ & $15(34 \cdot 9 \%)$ \\
Ashamed & $28(25 \cdot 4 \%)$ & $5(11 \cdot 6 \%)$ \\
Unable to understand & & $8(18 \cdot 6 \%)$ \\
where they came from & $41(37 \cdot 3 \%)$ & $80(46 \cdot 5 \%)$ \\
A bit of a nuisance & $28(25 \cdot 4 \%)$ & $20)$ \\
Should have come & $26(23 \cdot 6 \%)$ & $10(23 \cdot 2 \%)$ \\
$\quad$ sooner & $38(34 \cdot 5 \%)$ & $7(16 \cdot 3 \%)$ \\
Upset & $10(9 \cdot 1 \%)$ & $2(4 \cdot 6 \%)$ \\
Disbelief & $24(21 \cdot 8 \%)$ & $5(11 \cdot 6 \%)$ \\
Shock & $6(5 \cdot 4 \%)$ & $3(7 \cdot 0 \%)$ \\
Guilt & $5(4 \cdot 5 \%)$ & 0 \\
Something else & & \\
\hline
\end{tabular}

Multiple choice responses.
Table 2 Patients expressed concerns about the future

\begin{tabular}{lcc}
\hline Future concerns & $\begin{array}{c}\text { 1st Questionnaire } \\
(n=110)\end{array}$ & $\begin{array}{l}\text { 2nd Questionnaire } \\
(n=43)\end{array}$ \\
\hline No worries & $9(8 \cdot 2 \%)$ & $5(11 \cdot 6 \%)$ \\
Recurrence of warts & $87(79 \cdot 1 \%)$ & $37(86.0 \%)$ \\
Long term condom use & $29(26.4 \%)$ & $14(32 \cdot 5 \%)$ \\
Telling new partners & $12(10.9 \%)$ & $10(23 \cdot 2 \%)$ \\
Abnormal cancer smears & $34(30 \cdot 9 \%)$ & $11(25 \cdot 6 \%)$ \\
Passing on the virus & $49(44 \cdot 5 \%)$ & $21(48 \cdot 8 \%)$ \\
Pregnancy & $9(8 \cdot 2 \%)$ & 0 \\
Something else & $1(0 \cdot 9 \%)$ & 0 \\
Missing values & $4(3 \cdot 6 \%)$ & $1(2 \cdot 3 \%)$ \\
\hline
\end{tabular}

Multiple choice responses

needing repeated treatments and $6 \%$ felt concerned about washing before attending for treatment, with another $6 \%$ concerned about washing off podophyllin at work. Concerns remained after four weeks. Twenty five per cent of patients continued to feel embarrassed although this could be more to do with the examination than the actual presence of warts. Washing, either before attending clinic or washing off podophyllin remained a problem. There was less concern over discomfort (11\%) and fewer patients felt afraid or scared but there was a significant increase in concern over the need for repeated treatments $(51 \%)$.

Newly diagnosed patients were asked how they felt about having sex whilst warts were present. Seventeen per cent of patients had no current sexual partner but out of the remaining patients $33 \%$ were afraid of making the warts worse and $50 \%$ were afraid of passing on the virus. Other concerns were around issues of not wanting the partner to find out, afraid that sexual intercourse may hurt and dislike of condoms. From both samples approximately half the patients felt condom use was "No problem" ( $55 \%$ and $48 \%$ respectively). Nevertheless $29 \%$ in the newly diagnosed sample and $30 \%$ in the second sample still said that they disliked using condoms.

Both newly diagnosed patients and those who had had warts for four weeks expressed a number of concerns about the future (table 2).

The findings clearly highlight that having genital warts can never be of no consequence for patients and may often be traumatic. The patients in this study expressed a range of negative feelings, most of which reduced in degree but still persisted four weeks following diagnosis despite extensive counselling by the Health Advisor at first visit.

In severe cases such negative feelings may persist and lead on to severe psychological disorders. More generally the nature of feelings expressed here could result in low self esteem, poor body image, sexuality problems, relationship difficulties and stress. Stress if sufficiently severe may predispose the patient to recurrences and thereby result in a vicious circle being set up. 
Given the concerns expressed by patients about having sex whilst warts were present, there is a risk that the presence of genital warts may detrimentally affect the sexual activity of patients. This may be exacerbated by the requirement of long term condom use which are a constant reminder of warts.

The future concerns include the fear of recurrences, for women the need for annual cytological examinations, the risks of transmission, long term condom use and coping with sexual relationships. These all serve as a constant reminder to patients which reinforce negative feelings.

GUM staff need to be alerted to the psychological implications for patients and not to trivialise the effect of the negative feelings. Patients need good and appropriate counselling to help overcome negative emotions.

S WHEPPARE $M$ WALZMAN Department of Genitourinary Medicine Shepperton House George Elliot Hospital College St, Nuneaton CV10 7DF, UK

Address for correspondence: Ms S Sheppard.

1 Voog E, Gun-Britt L. Follow-up of men with genital papilloma virus infection: Psychological aspects. Acta Derm loma virus infection: Psychological

2 Persson G, Gösta Dahlöf L, Krantz I. Physical and psychological effects of anogenital warts on female patients. Sex Transm Dis 1993;20:10-3.

3 Filiberti A, Tamburini M, Stefanon B, et al. Psychologica aspects of genital human papillomavirus infection: a preliminary report. $\mathcal{F}$ Psychosom Obstet Gynaecol 1993;14: 145-52.

\section{Warts in the oral cavity}

The incidence of oral warts and their simultaneous occurrence and recurrence with genital warts is not known. A review of the literature implies that this entity (oral and concurrent genital warts) is rare. However, it is more likely that it is only rarely reported. This case report serves as a reminder to readers that oro-genital and oro-anal sex increase the anatomical sites of sexually transmitted diseases and risk of oral infections.

This is the case history of a 26 year old Caucasian man who attended the genitourinary medicine clinic in our Hospital, complaining of "warts" on his penis and lips for the past six months. He admitted to having one regular female sexual partner with whom he had both oral and vaginal sex regularly.

A genital examination revealed two small warts, one on the ventral surface and the other on the dorsal surface of the shaft of the penis. Careful inspection of his oral cavity showed two discrete papillomatous warty growths protruding from his upper inner lip (vide photograph). The warts were nontender and surrounded by normal mucosa. There were no other abnormalities of the oral cavity noted. The remainder of his skin was examined and appeared normal.

Apart from having a positive test for chlamydia, the other routine screening tests for sexually transmitted diseases were nega-

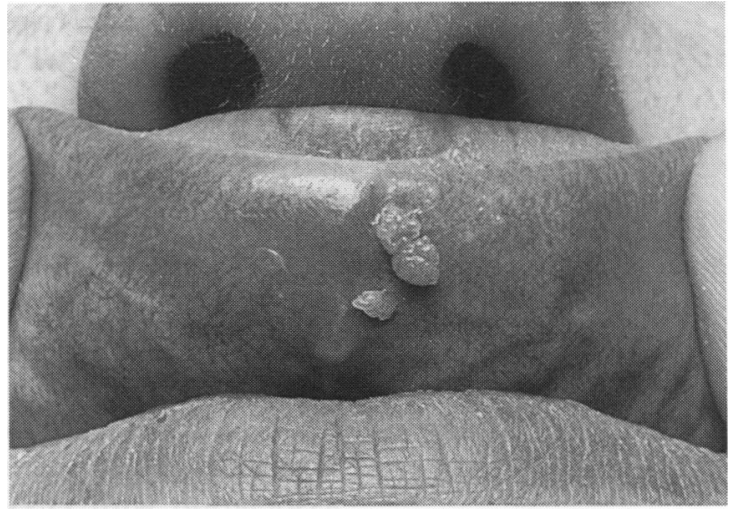

tive. The possibility of HIV testing was discussed. However, the patient did not wish to have this test performed.

The penile warts responded to podophyllin therapy. The warts on the lip were treated using cryocautery. The chlamydia infection was treated with a course of oral tetracyclines.

Genital warts are caused by the human papilloma virus (HPV). In 1901, Heidingsfield reported the case of a 24 year old "puella publica" who was suspected of acquiring genital warts of the tongue as a result of "coitus illegitimus"." Although the pejorative terms used to describe the above occurrence have long been abandoned, the genital to oral route of transmission was probably the same as that postulated for this patient. Heidingsfield performed detailed histological studies of the wart specimens from both the tongue and labia of his patient and concluded that "Condylomata acuminata" of the lips conforms not only in clinical character but also in histological structure to Condylomata acuminata of the genital location.

Oral transmission of HPV from genital warts has not been clearly determined but it appears that most mucous membranes of the oral cavity may be susceptible. Condylomata acuminata has been reported to involve the mucosa of the gingiva, ${ }^{23}$ cheeks, $^{3-5}$ hard palate $^{3}$ and tongue. ${ }^{136}$ Uncommon sites for wart infection are more likely to occur in immuno-compromised states such as seen in HIV patients.

This case serves to remind us that we should always examine the oral cavity carefully in those patients who admit to having oral sex.

A KUNDU A A H WADE Department of Genitourinary Medicine Coventry and Warwickshire Hospital, Stoney Stanton Road,
Coventry CV1 $4 F H, U K$

Accepted for publication 26 January 1995

1 Heidingsfield ML. Condylomata acuminata lingue (venereal warts of the tongue). $\mathcal{f}$ Cutaneous Genito-Urinary Disease 1901;19:226-34.

2 Knapp MJ, Vohara GI. Oral condyloma acuminatum. Oral Surg 1967;23:538-45.

3 Seibert JS, Shannon CJ, Jacoway JR. Treatment of recurrent condyloma acuminatum. Oral Surg 1969;27: rent condy

4 Markelov VP. Affection of the vermilion border and mucous membrane of the lips in a patient with condyloma acuminatum. Vestn Dermatol Venerol 1971;45:69.

5 Summers L, Booth DR. Intraoral condyloma acuminatum. Oral Surg 1974;38:273-8.

6 Oriel JD. Genital warts. Sex Transm Dis 1977;4:153-9. 